\title{
Pengaruh Luas Lubang Pipa Pada Kolom Pendek Dengan Variasi Diameter Lubang Pipa 11/2”, 2”, 21/2” Dan 3”.
}

\author{
${ }^{1}$ Agus Sugianto, ${ }^{2}$ Andi Marini Indriani, ${ }^{3}$ Ismail Husein \\ ${ }^{1,2}$ Dosen Program Studi Teknik Sipil dan Perencanaan Universitas Balikpapan, \\ Email: agus.fadhil@yahoo.co.id \\ Email : marini_sabrina@yahoo.com.sg \\ ${ }^{3}$ Mahasiswa Fakultas Teknik Sipil dan Perencanaan Universitas Balikpapan,
}

\begin{abstract}
The use of holes in the manufacture of a column that serves as the placement of sewer commonly found in multi-storey buildings. Understanding of the construction perpetrators of the ideal aperture area of the column need attention so that the ability of the column structure remains fulfilled and a review of functionality also remains accommodated. This research was conducted in the form of short column with concrete cylinder models which were given hole with varied wide then doing test press. The methodology used in this study with the manufacture of concrete cylinder compressive strength of $20 \mathrm{MPa}$. and variations in the diameter of the pipe hole $\varnothing 1 \frac{1}{2} 2$ ", 2 ", 2 1/2 "and $3 "$ using PVC pipe to mold a hole in the concrete cylinders. Making the hole refers to the standard of making holes in concrete columns up to $4 \%$ of the cross sectional area of concrete in accordance with SNI 032847 2002. Results of the study provide the conclusion that the ratio between the diameter of the hole $\varnothing 1 \frac{1}{2}$ ", 2", $21 / 2$ "and 3" on the concrete cylinders are any additions to the aperture area of $0.015 \mathrm{~cm} 2$ compressive strength decreased by $0.02 \%$ against the concrete cylinder diameter of $15 \mathrm{~cm}$ and height $30 \mathrm{~cm}$, Making holes in concrete columns resulted in a reduction in compressive strength of concrete.
\end{abstract}

Keywords: wide variation hole, cylinder concrete, short columns.

\begin{abstract}
Abstrak
Pemakaian lubang dalam pembuatan kolom yang berfungsi sebagai penempatan saluran pembuangan banyak ditemui pada bangunan-bangunan bertingkat. Pemahaman para pelaku konstruksi terhadap luas lubang ideal pada kolom perlu mendapat perhatian agar kemampuan struktur kolom tetap terpenuhi dan tinjauan terhadap fungsi juga tetap terakomodir. Penelitian ini dilakukan pada kolom pendek dengan model berupa silinder beton yang diberi lubang dengan luas bervariasi kemudian dilakukan uji tekan. Metodologi yang dipakai dalam penelitian ini dengan pembuatan silinder beton

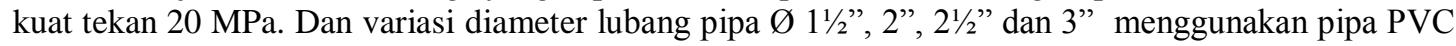
untuk cetakan lubang pada silider beton. Pembuatan lubang mengacu pada standar pembuatan lubang pada kolom beton maksimal 4\% dari luas penampang beton sesuai dengan SNI 032847 2002. Hasil penelitian memberikan kesimpulan bahwa perbandingan antara diameter lubang $\varnothing 1 \frac{112}{2}, 2$ ", 21/2" dan 3 " pada silinder beton adalah setiap penambahan luas lubang $0,015 \mathrm{~cm}^{2}$ terjadi penurunan kuat tekan sebesar $0,02 \%$ terhadap silinder beton diameter $15 \mathrm{~cm}$ dan tinggi $30 \mathrm{~cm}$. Pembuatan lubang pada kolom beton mengakibatkan terjadinya penurunan kuat tekan beton.
\end{abstract}

Kata kunci : Variasi luas lubang, Silinder beton, kolom pendek. 


\section{Pendahuluan}

\subsection{Latar Belakang}

Beton adalah bahan yang sangat luas digunakan untuk berbagai konstruksi. Karena beton bukan material yang elastis, dengan perilaku ketidak linierannya mulai dari tahap pembebanan yang paling awal, ada beberapa penelitian yang cukup mengenai kontrol serviceability, yaitu perilaku rangkak, lendutan dan perilaku jangka panjang pada beton. Semakin banyaknya pemakaian beton di dalam industri konstruksi, maka semakin banyak pula usaha untuk membuatnya semakin canggih dan semakin ekonomis. Kecanggihan itu dinyatakan dalam pembuatan beton dengan mutu yang tinggi, sementara biaya berusaha ditekan serendah mungkin.

Era pembangunan saat ini banyak sekali permasalahan yang dihadapi dalam penentuan penempatan saluran pembuangan khususnya sanitasi. Salah satu contoh yang sering kali kita temukan yaitu, penempatan saluran pembuangan yang terbuka dan dapat dilihat secara langsung dapat mengurangi estetika bangunan itu sendiri serta tidak baik dilihat dari segi konstruksi bangunannya. Maka para pelaku konstruksi atau pemilik bangunan berusaha untuk meletakkan pipa air hujan dengan tersembunyi dan pada umumnya diletakkan dalam kolom beton.

Permasalahan yang terjadi adalah bagaimana pengaruh pemakaian lubang pipa dengan diameter yang berbeda yaitu: (11/2", 2", 21/2" dan 3") pada kolom beton terhadap kuat tekan beton dan seberapa besar persentase pengaruh lubang pada kolom pendek dengan model silinder yang digunakan diameter $15 \mathrm{~cm}$ dan tinggi $30 \mathrm{~cm}$

Batasan penelitian ini adalah : a. Beton yang digunakan adalah beton normal dengan kuat tekan beton $\left(f \mathrm{c}^{\prime}\right)=20 \mathrm{Mpa}$.

b. Lubang Pipa yang digunakan yaitu diameter $1 \frac{1}{2}, ", 2 ", 2 \frac{1}{2}$ ", dan 3".

c. Tidak membahas Mix Design beton.

\section{Metode Penelitian}

\subsection{Umum}

Metode penelitian adalah suatu rangkaian pelaksanaan penelitian yang bertujuan mencari jawaban atas suatu permasalahan penelitian, agar dapat berjalan dengan sistematis, baik dan lancar dan dapat mencapai tujuan yang di inginkan maka tidak terlepas dari metode penelitian dengan menyesuaikan metode/jenis penelitian.

Bahan yang digunakan :

a. Semen Portland jenis 1 merk Gresik kemasan $50 \mathrm{~kg}$,

b. Agregat pasir Samboja dan pasir Palu,

c. Agregat kasar yang dipergunakan yaitu spilt $2 / 3$,

d. Benda uji yang akan digunakan adalah beton silinder diameter 15 $\mathrm{cm}$ dan tinggi $30 \mathrm{~cm}$ dengan kuat tekan yang direncanakan $20 \mathrm{MPa}$.

\subsection{Metode Pelaksanaan Pengujian Di laboratorium}

Metode pelaksanaan penelitian ini dengan membuat model kolom pendek yang diberi lubang dengan diameter $1 \frac{1}{2}$ ", 2", 21/2" dan 3" dan diuji tekan dengan umur beton 3 hari, 7 hari dan 28 hari.

\section{Hasil dan Pembahasan}

\subsection{Pengujian Kuat Tekan Beton Dengan Variasi Lubang}


Hasil pengujian kuat tekan beton selengkapnya disajikan dalam Tabel 5.4 dengan nilai slump $10 \mathrm{~cm}$.

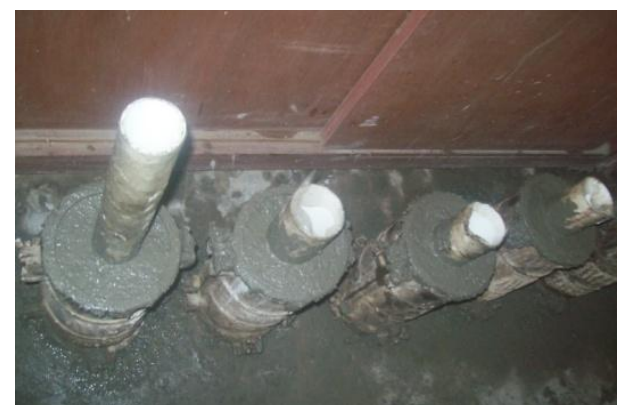

Gambar 3.1 Model pengujian silinder beton

\section{A. Umur Beton 3 hari}

Berikut ini dilampirkan tabel dan grafik pengujian beton pada umur 3 hari.

Tabel 3.1 Hasil Pengujian Kuat Tekan Beton Umur 3 Hari.

\begin{tabular}{|l|l|l|l|l|}
\hline $\begin{array}{l}\text { Jenis } \\
\text { Beton } \\
\text { Variasi }\end{array}$ & $\begin{array}{l}\text { Kode } \\
\text { Benda } \\
\text { Uji }\end{array}$ & $\begin{array}{l}\text { Beban } \\
\text { Maksi } \\
\text { mum } \\
(\mathbf{k g} / \mathbf{c} \\
\left.\mathbf{m}^{2}\right)\end{array}$ & $\begin{array}{l}\text { Luas } \\
\text { Tampa } \\
\text { ng } \\
\left(\mathbf{c m}^{2}\right)\end{array}$ & $\begin{array}{l}\text { Kuat } \\
\text { Tekan } \\
(\mathbf{M P a})\end{array}$ \\
\hline Normal & BN-IH1 & 2200 & 176,625 & 12.45 \\
\hline Ø 11/2” & BV-IH2 & 2200 & 165.230 & 8.47 \\
\hline Ø 2" & BV-IH3 & 2200 & 165.375 & 7.86 \\
\hline Ø 21/2” & BV-IH4 & 2200 & 144.975 & 7.58 \\
\hline Ø 3" & BV-IH5 & 2200 & 131.045 & 6.86 \\
\hline
\end{tabular}

Dari Tabel 3.1 didapat beton (BV-IH1), Luas penampang $176,625 \mathrm{~cm}^{2}$ dengan kuat tekan $=12.45 \mathrm{MPa},(\mathrm{BV}-\mathrm{IH} 2)$, Luas penampang $165,230 \mathrm{~cm}^{2}$ dengan kuat tekan $=8.47 \mathrm{Mpa},(\mathrm{BV}-\mathrm{IH} 3)$, Luas penampang $165,375 \mathrm{~cm}^{2}$ dengan kuat tekan $=7.58 \mathrm{Mpa}$, (BV-IH4), Luas penampang 144,975 $\mathrm{cm}^{2}$ dengan kuat tekan pada umur 3 hari $=7.58 \mathrm{Mpa}$, (BV-IH5), Luas penampang 131,045 $\mathrm{cm}^{2}$ dengan kuat tekan $=6.86 \mathrm{Mpa}$ pada umur beton 3 hari pada rasio $(\mathrm{BN}$ IH1);(BV-IH2);(BV-IH3);(BV-IH4) dan (BV-IH5) dengan perbandingan Rasio 1 : $0.67: 0.63: 0.60: 0.54$.

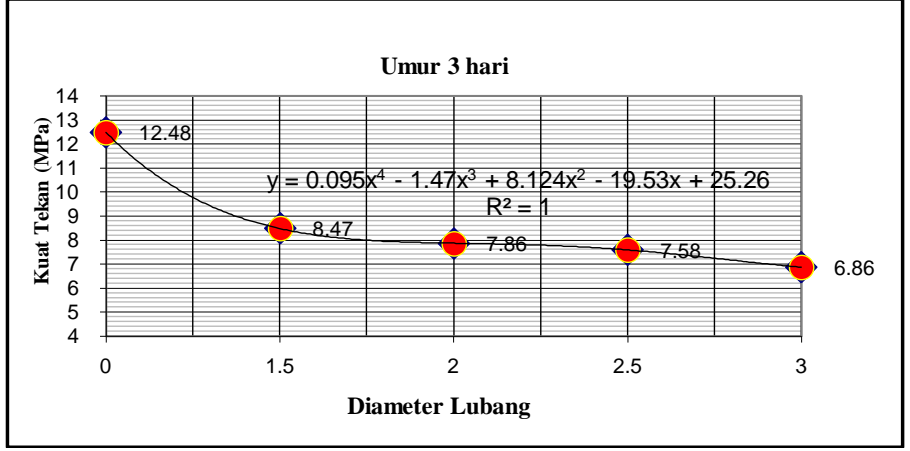

Gambar 3.2 kurva kuat tekan diameter lubang pada umur beton 3 hari.

Gambar 3.2 kurva menunjukkan untuk $\varnothing 1 \frac{1}{2} "=8,47 \mathrm{MPa}, \varnothing 2 "=7,86 \mathrm{MPa}$, $\varnothing 2 \frac{1 / 2 "}{2}=7,58 \mathrm{MPa}, \varnothing 3 "=6,68 \mathrm{MPa}$ dan persamaan nilai rata-rata adalah $y=0,095 x^{4}-1,47 x^{3}+8,124 x^{2}-19,53 x$ - 25,26 dengan kurva regresi $R^{2}=1$ (nilai terbaik regresi $\leq 1$ ) dan $\mathrm{y}=$ Kuat tekan $(\mathrm{MPa}) \mathrm{x}=$ Diameter lubang (Inchi).

\section{B. Umur Beton 7 Hari}

Berikut ini dilampirkan tabel dan grafik pengujian beton pada umur 7 hari.

Tabel 3.2 Hasil Pengujian Kuat Tekan Beton Variasi Umur 7 Hari.

\begin{tabular}{|c|c|c|c|c|}
\hline $\begin{array}{l}\text { Jenis } \\
\text { Beton } \\
\text { Variasi }\end{array}$ & $\begin{array}{l}\text { Kode } \\
\text { Benda } \\
\text { Uji }\end{array}$ & $\begin{array}{l}\text { Beban } \\
\text { Maksi } \\
\text { mum } \\
(\text { Kg/c } \\
\text { m²) }^{2}\end{array}$ & $\begin{array}{l}\text { Luas } \\
\text { Tampa } \\
\text { ng } \\
\left(\mathbf{c m}^{2}\right)\end{array}$ & $\begin{array}{l}\text { Kuat } \\
\text { Tekan } \\
\text { (MPa) }\end{array}$ \\
\hline Normal & BN-IH11 & 2950 & 166.625 & 16.70 \\
\hline Ø 11/2" & BV-IH12 & 2100 & 165.230 & 12.71 \\
\hline Ø 2" & BV-IH13 & 1750 & 156.375 & 11.19 \\
\hline Ø 21/2" & BV-IH14 & 1500 & 144.975 & 10.34 \\
\hline Ø 3" & BV-IH15 & 1350 & 131.045 & 10.30 \\
\hline
\end{tabular}

Dari Tabel 3.2 didapat untuk kuat tekan minimum pada luas lubang diameter $3 "=9,92$ dan kuat tekan maksimum pada beton normal $=19,98 \mathrm{MPa}$ dan yang mendekati nilai untuk beton normal adalah pada luas lubang dengan diameter $1 \frac{1}{2} "=13,31 \mathrm{MPa}$ pada umur beton 7 hari pada rasio (BN-IH11);(BVIH12);(BV-IH13);(BV-IH14) dan (BV- 
IH15) dengan perbandingan Rasio 1 : $0.76: 0.70: 0.64: 0.58$ terhadap rasio perbandingan (BN-IH11).

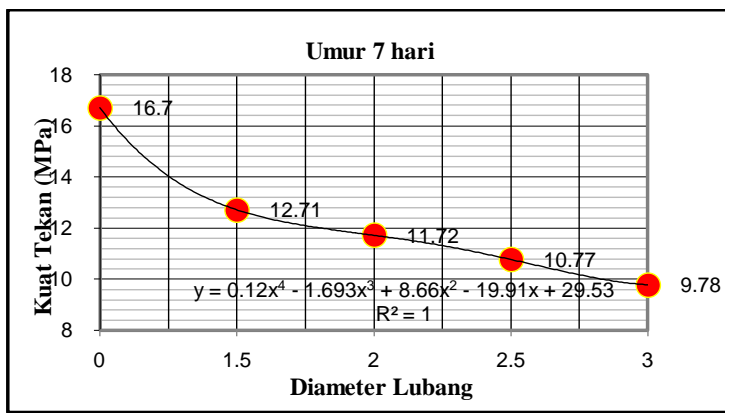

Gambar 3.3. kurva kuat tekan diameter lubang pada umur beton 7 hari.

Gambar 3.3. kurva pengujian tekan menunjukkan untuk $\varnothing 1 \frac{1 / 2 "}{2}=12,71$ $\mathrm{MPa}, \varnothing 2 "=11,72 \mathrm{MPa}, \quad \varnothing 2 \frac{1}{2} "=$ 10,77 MPa, Ø3"=9,78 MPa dan persamaan nilai rata-rata adalah $y=0,12 x^{4}-1,693 x^{3}+8,66 x^{2}-19,91 x$ - 29,53 dengan kurva regresi $\mathrm{R}^{2}=1$ (nilai terbaik regresi $\leq 1$ ) dan $\mathrm{y}=$ Kuat tekan (MPa) $\mathrm{x}=$ Diameter lubang (Inchi).

\section{Umur Beton 28 Hari}

Berikut ini dilampirkan tabel dan grafik pengujian beton pada umur 28 hari.

Tabel 3.3 Nilai rata-rata Hasil Pengujian Kuat Tekan Beton Variasi Umur 28 Hari.

\begin{tabular}{|c|c|c|c|c|}
\hline No. & $\begin{array}{c}\text { Variasi } \\
\text { Luas } \\
\text { lubang } \\
\text { (Inch) }\end{array}$ & $\begin{array}{c}\text { Luas } \\
\text { Bidang } \\
\left(\mathbf{C m}^{2}\right)\end{array}$ & $\begin{array}{c}f \mathrm{c}^{\prime} \\
28 \text { hari }\end{array}$ & $\begin{array}{l}\text { Persen Luas } \\
\text { Lubang } \\
\text { Penampang }\end{array}$ \\
\hline 1 & $0 \%$ & 176,625 & 26.646 & \\
\hline 2 & $0 \%$ & 176,625 & 25.769 & \\
\hline 3 & $1 \frac{1 / 2 "}{2}$ & 165,230 & 20.892 & \multirow{2}{*}{0,93} \\
\hline 4 & $11 / 2 "$ & 165,230 & 19.000 & \\
\hline 5 & $2 "$ & 156,375 & 18.062 & \multirow{2}{*}{0,88} \\
\hline 6 & $2 "$ & 156,375 & 17.062 & \\
\hline 7 & $2 \frac{1}{2} "$ & 144,975 & 17.323 & \multirow{2}{*}{0,82} \\
\hline 8 & $2 \frac{1}{2} 2^{\prime \prime}$ & 144,975 & 14.738 & \\
\hline 9 & 3" & 131,045 & 16.769 & \multirow{2}{*}{0,74} \\
\hline 10 & 3" & 131,045 & 15.569 & \\
\hline
\end{tabular}

Dari Tabel 3.3 didapat untuk kuat tekan minimum pada luas lubang diameter $3 "=15,569 \mathrm{MPa}$ dan kuat tekan maksimum untuk beton normal =
26,646 MPa dan yang mendekati nilai untuk beton normal adalah pada luas lubang dengan diameter $1 \frac{1}{2} "=20,892$ MPa pada umur beton 28 hari dengan perbandingan Rasio $1: 0.76: 0.67$ : $0.61: 0.62$.

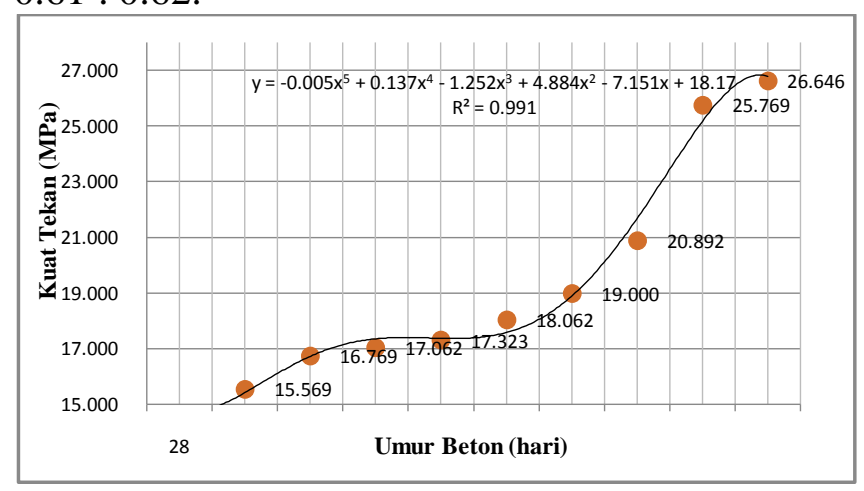

Gambar 3.4 kurva kuat tekan umur beton 28 hari.

Gambar 3.4 kurva pengujian kuat tekan menunjukkan untuk $\varnothing 1 \frac{1 / 2 "}{2}=20,892$ $\mathrm{MPa}, \varnothing 2 "=18,062 \mathrm{MPa}, \quad \varnothing 2 \frac{1}{2} "=$ $17.323 \mathrm{MPa}, \varnothing 3 "=16,769 \mathrm{MPa}$ dan persamaan nilai rata-rata adalah $\mathrm{y}=$ $-0,005 x^{5}+0,137 x^{4}-1,252 x^{3}+4,884 x^{2}$ $-7,151 x-18,17$ dengan kurva regresi $\mathrm{R}^{2}=1$ (nilai terbaik regresi $\leq 1$ ) dan $\mathrm{y}=$ Kuat tekan (MPa) $\mathrm{x}=$ Umur beton (hari).

\subsection{Kurva Persamaan Rasio Pada Luas Lubang Ø 11/2", 2", 21/2" dan 3".}

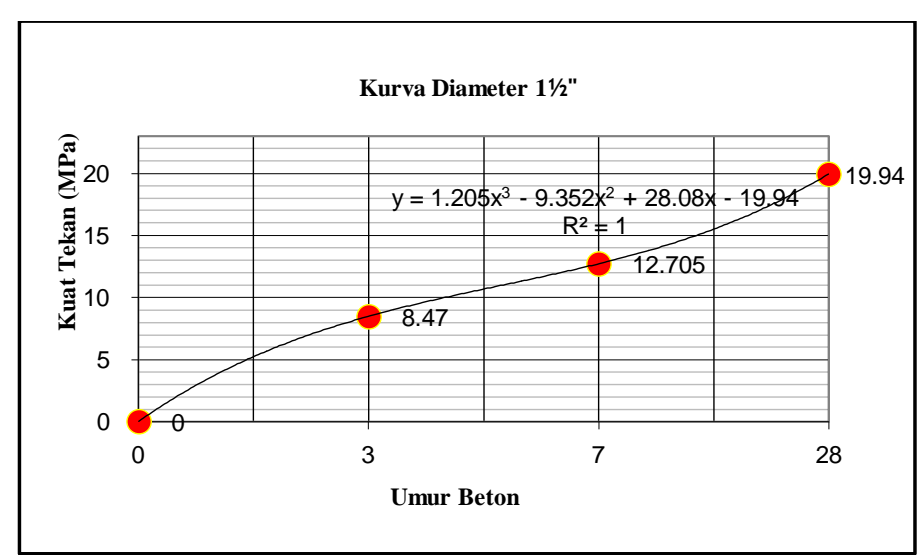

Gambar.3.5 kurva rasio persamaan diameter $1 \frac{1}{2} "$. 
Gambar 3.5 kurva pengujian kuat tekan menunjukkan umur beton 3 hari $=8,47$ $\mathrm{MPa}, 7$ hari $=12,705 \mathrm{MPa}, 28$ hari $=$ $19,94 \mathrm{MPa}$ dan persamaan nilai rata-rata adalah $y=1,205 x^{3}-9,352 x^{2}+28,08 x-$ 19,94 dengan kurva regresi $\mathrm{R}^{2}=1$ (nilai terbaik regresi $\leq 1$ ) dan $\mathrm{y}=$ Kuat tekan (MPa) $\mathrm{x}=$ Umur beton (hari).

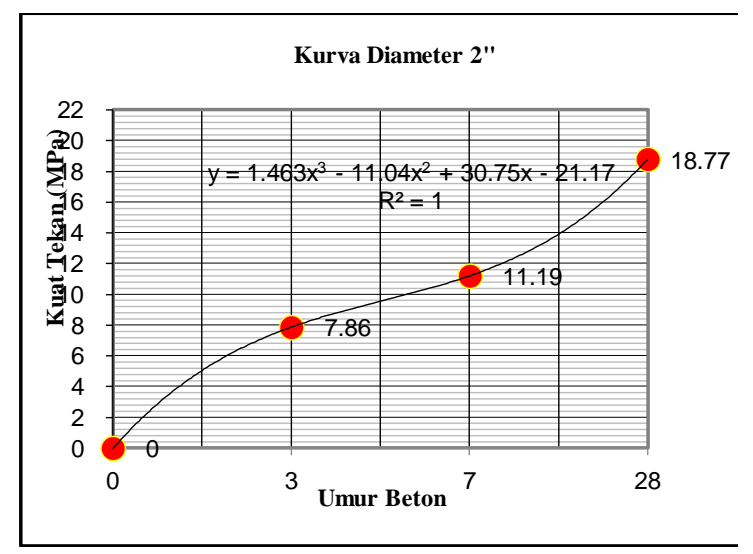

Gambar 3.6 Kurva rasio persamaan diameter 2".

Gambar 3.6 kurva menunjukkan umur beton 3 hari $=7,06 \mathrm{MPa}, 7$ hari $=11,19 \mathrm{MPa}, 28$ hari $=18,77 \mathrm{MPa}$ dan persamaan nilai rata-rata adalah adalah $y=1,463 x^{3}-11,04 x^{2}+30,75 x-21,17$ dengan kurva regresi $\mathrm{R}^{2}=1$ (nilai terbaik regresi $\leq 1$ ) dan $\mathrm{y}=$ Kuat tekan (MPa) $\mathrm{x}=$ Umur beton (hari).

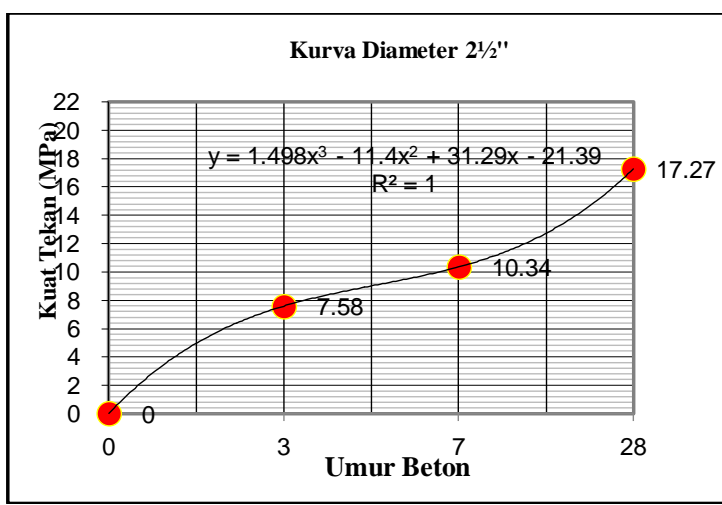

Gambar 3.7 Kurva rasio persamaan diameter $2 \frac{1 / 2 "}{2}$.

Gambar 3.7 kurva pengujian kuat tekan menunjukkan untuk 3 hari $=7,68 \mathrm{MPa}$, 7 hari $=10,34 \mathrm{MPa}, \quad 28$ hari $=17,27$ $\mathrm{MPa}$ dan persamaan nilai rata-rata adalah $\mathrm{y}=1,498 \mathrm{x}^{3}-11,4 \mathrm{x}^{2}+31,29 \mathrm{x}-$ 21,39 dengan kurva regresi $\mathrm{R}^{2}=1$ (nilai terbaik regresi $\leq 1$ ) dan $\mathrm{y}=$ Kuat tekan (MPa) $\mathrm{x}=$ Umur beton (hari).

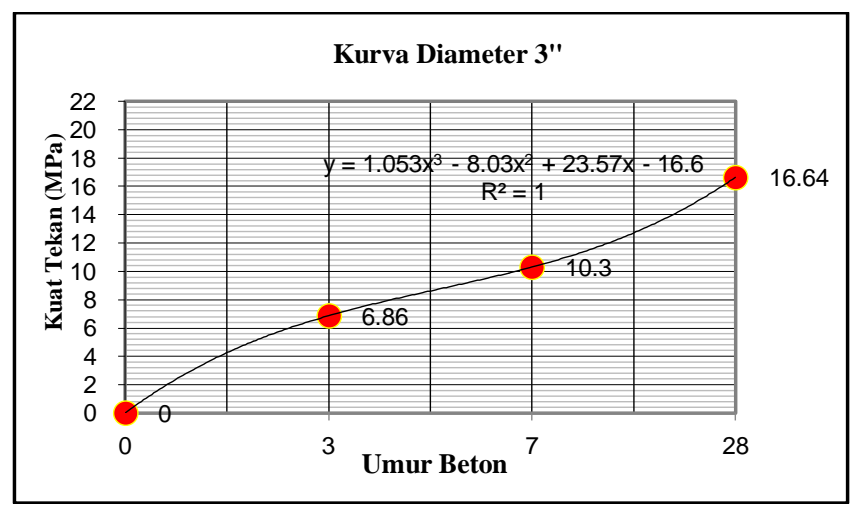

Gambar 3.8 Kurva rasio persamaan diameter 3".

Gambar 3.8 kurva pengujian kuat tekan menunjukkan untuk 3 hari $=6,86 \mathrm{MPa}$, 7 hari $=10,30 \mathrm{MPa}, 28$ hari $=16,64$ $\mathrm{MPa}$ dan persamaan nilai rata-rata adalah $\mathrm{y}=1,053 \mathrm{x}^{3}-8,03 \mathrm{x}^{2}+16,6 \mathrm{x}$ dengan kurva regresi $\mathrm{R}^{2}=1$ (nilai terbaik regresi $\leq 1$ ) dan $\mathrm{y}=$ Kuat tekan (MPa) $\mathrm{x}=$ Umur beton (hari).

\subsection{Analisis Hasil Penelitian.}

a. Hasil perbandingan kuat tekan untuk diameter $1 \frac{1}{2} ", 2 ", 2 \frac{1}{2}$ " dan 3" adalah luas lubang pada penampang silinder beton akan mempengaruhi penurunan kuat tekan.

b. Perbandingan luas penampang untuk silinder beton normal dengan luas penampang $=166,625 \mathrm{~cm}^{2}$ dan pengurangan pada silinder beton variasi dengan diameter $1 \frac{1}{2}$ " luas penampang $=165,230 \mathrm{~cm}^{2}$, diameter 2" luas penampang = $156,375 \mathrm{~cm}^{2}$, diameter $2 \frac{1}{2}$ " luas penampang $=144,975 \mathrm{~cm}^{2}$ dan diameter 3" luas penampang = $131,045 \mathrm{~cm}^{2}$ kemudian untuk perbandingan rasio pada umur 3 hari $=1: 0.67: 0.63: 0.60: 0.54,7$ hari $=1: 0.76: 0.70: 0.64: 0.58$, dan 28 hari $=1: 0.76: 0.67: 0.62$ : 0.61 . 


\section{Kesimpulan}

1. Terjadi penurunan kuat tekan beton akibat adanya lubang.

2. Persentase luas lubang terhadap penurunan kuat tekan beton yaitu :

a. Pertambahan luas lubang 0,05 $\mathrm{cm}^{2}$ maka terjadi penurunan kuat tekan sebesar $0,88 \%$.

b. Pertambahan luas lubang 0,06 $\mathrm{cm}^{2}$ maka terjadi penurunan kuat tekan sebesar $0,92 \%$.

c. Pertambahan luas lubang 0,08 $\mathrm{cm}^{2}$ maka terjadi penurunan kuat tekan sebesar $0,98 \%$.

Setiap penambahan luas lubang $0,015 \mathrm{~cm}^{2}$ terjadi penurunan kuat tekan sebesar $0,02 \%$ dengan silinder beton diameter $15 \mathrm{~cm}$ dan tinggi 30 $\mathrm{cm}$.

\section{Daftar Pustaka}

1.Anonim, 2002, Tata Cara Perhitungan Struktur Beton Untuk Bangunan Gedung SNI, Bandung, Desember 2002.

2.Anonim,2002, Baja Tulangan Beton,SNI 07-2052-2002,Jakarta.
3.Anonim, 2008,Cara Uji Slump Beton, SNI 1972:2008,Jakarta.

4.Dipohusodo, 1994, Struktur Beton Bertulang, Penerbit PT Gramedia Pustaka Utama, Jakarta, 10207.

5.Edward. G. Nawy, Tavio, \& Benny Kusuma, 2010, Beton Bertulang, Edisi ke-5, Penerbit ITS Press, Surabaya 60111.

6.H. Alis. Asroni, 2010, Balok Dan Pelat Beton Bertulang, Penerbit Graha Ilmu, Yogyakarta 55283.

7.L. J. Murdock, K. M. Brook, 1981,Bahan dan Praktek Beton, Edisi ke-4, Penerbit Erlangga, Jakarta, 10420.

8.Sadji,2006,Material Beton Dan Persyaratannya, Penerbit ITS dan HAKI, Surabaya 60111.

9.Tri Mulyono, 2005, Teknologi Beton, Penerbit CV. Andi Offset, Yogyakarta 55281.

10. W. C. Vis, \& Gideon Kusuma,1993, Dasar Perencanaan Beton Bertulang, Penerbit Erlangga, Jakarta 13740. 